\title{
Políticas Urbanas no Brasil: marcos legais, sujeitos e instituições
}

Resumo: A questão urbana no Brasil - traduzida como o direito à cidade e à moradia digna - nas três últimas décadas passou por intensas transformações tanto em seus marcos regulatórios quanto na forma de envolvimento das diferentes instituições e sujeitos localizados na sociedade e no aparato estatal. Desde os debates que antecederam a Assembleia Nacional Constituinte na década de 1980, a mobilização tem sido intensa e marcada por tensões entre os diversos atores. Busca-se demonstrar as incorporações de diferentes sujeitos por meio de processos democráticos participativos, como conselhos e conferências, os resultados obtidos por meio da consolidação de legislação específica e os limites atuais da Política Urbana.

Palavras-chave: Política Urbana; Participação Democrática; Desenvolvimento Urbano; questão urbana; democracia deliberativa

Abstract: The urban question in Brazil - translated as the right to the city and to dignity housing - in the three last decades has passed by intense transformations in its regulatory landmarks and in its forms of involvement of different institutions and citizens located in the society and in state apparatus. Since the debates that had preceded the National Constituent Assembly, in the decade of 1980, the mobilization has been intense and marked by tensions between diverse actors. We aim to demonstrate the incorporations of different citizens by democratic participatory processes, such as councils and conferences, the achievements of the consolidation of specific legislation and current limits of the Urban Policy.

Keywords: Urban Policy; Democratic Participation; Urban Development; Urban Question; Deliberative Democracy

\footnotetext{
A implementação de uma política urbana vigorosa depende de uma quantidade expressiva de recursos públicos e de diretrizes da política pública estruturada e com continuidades ao longo do tempo. A eficácia da política não se estabelece apenas no interior do aparato estatal, mas na interseção de interesses e projetos com a sociedade civil. Ao longo do texto, buscar-se-á apontar justamente o imenso vigor da esfera pública e dos movimentos sociais em torno da questão urbana.
}

Ao retrocedermos em duas décadas, verificamos que a Constituição Brasileira,

Recebido:

21.05.09

Aprovado:

29.10.12

1. Professora Associada do Programa de Pós-Graduação em Ciências Sociais da Universidade Estadual de Maringá. Mestre em Ciência Política pela Unicamp. Doutora em História pela Unesp, com Pós-doutorado pelo Programa de Pós-Graduação em Ciências Sociais da PUC-SP. Pesquisadora da Rede Observatório das Metrópoles - Institutos Nacionais (CNPq), 2009-2013. Bolsista Produtividade da Fundação Araucária. Autora do livro: "Poder local e políticas públicas - o papel dos conselhos gestores" (Eduem, 2006). Organizadora do livro "Retratos da Região Metropolitana de Maringá - subsídios para a elaboração de políticas públicas participativas" (Eduem, 2010), entre outras publicações.

E-mail: ctonella@ uol.com.br 
promulgada em 1988, foi precedida de intensa mobilização social para garantir a incorporação de demandas de inúmeros setores. Servem de base de reflexão dois aspectos presentes no texto constitucional. O primeiro destes diz respeito às diretrizes do Capítulo II, dedicado à política urbana. O segundo aspecto está ligado aos mecanismos que garantiram a possibilidade de participação ampliada da sociedade nos processos de formatação das políticas públicas, os quais se mostraram fundamentais para o desenho atual da democracia no Brasil. A Constituição foi saudada como progressista, na medida em que reconhecia formalmente uma série de novos direitos e criava novos mecanismos de participação política ao lado dos tradicionais procedimentos da democracia representativa. $\mathrm{O}$ arcabouço jurídico para a estruturação tanto da legislação específica da política quanto dos mecanismos de controle social estavam presentes no texto constitucional.

A luta pela redemocratização do Brasil somou-se à reivindicação dos movimentos sociais por maior participação nas tomadas de decisões, requerendo, para isso, a criação de instituições participativas e de debates públicos. Parte da literatura contemporânea sobre o tema rompe com a visão maniqueísta, que contrapunha Estado e sociedade, e aponta para uma relação menos dicotomizada e marcada por algumas sinergias (DAGNINO, 2002; LAVALLE, 2003; DAGNINO, OLVERA e PANFICHI, 2006 e MOURA e SILVA, 2008). O ponto focal do debate é o entendimento de que não há um comportamento homogêneo de grupos que compõem a sociedade civil, nem dos agentes estatais.

O artigo está divido em três partes. No item os marcos legais da política urbana, são discutidas mudanças ocorridas no pós-constituição. Os anos 1990 marcaram a reforma do Estado, tendo, de um lado, a privatização de diversas áreas das políticas públicas, descentralização, proposição de fortalecimento do poder local e de outro o reforço do discurso participacionista vinculado à normatização em leis específicas de artigos da Constituição de 1988. No plano institucional, no início do século XXI, verificou-se uma correção de rumos importante nas políticas urbanas quando, em 2003, no governo Lula, o Ministério das Cidades passa a compor o Executivo Federal, o que representou o primeiro passo na direção do tratamento das políticas urbanas de forma integrada.

No segundo item, os espaços da democracia deliberativa, são explicitadas as principais estruturas de participação ampliada: o Conselho das Cidades e as Conferências. O Conselho Nacional das Cidades foi criado em 2004 como resultante de mobilizações ocorridas no País, que culminou com as Conferências das Cidades nos três níveis administrativos. O Conselho passou a representar um importante instrumento de elaboração de políticas urbanas. Pressupõe, segundo a sua composição, a possibilidade de explicitação de interesses entre as esferas de poder e a sociedade organizada. 
Por fim, no item 3, a visibilidade dos movimentos sociais, aponta-se o protagonismo de diversos movimentos sociais urbanos na estruturação da Política Urbana e em seus desdobramentos.

\section{Os marcos legais da política urbana}

As lutas sociais articuladas em torno da derrubada do regime militar ao longo dos anos, de 1970 a início de 1980, contribuíram para que a questão urbana ganhasse a cena política. Inúmeras entidades que estavam organizadas em bairros periféricos, em torno de segmentos profissionais, de gênero e etnia, articularam-se em nível nacional e desembocaram na elaboração de uma proposta para a Assembleia Nacional Constituinte de 1986, concretizada na proposta de Emenda Popular da Reforma Urbana. Por todo o País, uma teia de movimentos populares estruturou-se a partir de suas questões específicas, mas contribuindo para o fortalecimento do todo: mutuários do $\mathrm{BNH}$, inquilinos, loteamentos clandestinos e irregulares, moradores de cortiços, favelados, mutirantes etc..

A partir da Constituinte, que gerou a Constituição promulgada em 5 de outubro de 1988, "abriu-se um processo de reforma institucional, especialmente no plano local" (RIBEIRO e SANTOS Jr., 1994, p. 5). O autor observa que as reformas no arcabouço jurídico dos municípios, após a promulgação da Carta, buscaram um novo modelo de política e gestão da cidade: democrática em relação às condições e atores de processo decisório governamental, universalista no que diz respeito aos direitos sociais na cidade e redistributiva dos ônus e custos da urbanização. Estavam estabelecidos os parâmetros para a construção dos marcos legais subsequentes.

A nova orientação influenciou as Constituições Estaduais e as Leis Orgânicas dos Municípios, obrigatórias para os com mais de 20 mil habitantes. Concretamente, a nova orientação constitucional aponta para o abandono da ideia de planejamento urbano e substitui-a pela concepção de gestão, mostrando quais os elementos que as prefeituras dispõem para gerir recursos, no sentido de uma maior equidade. A Constituição de 1988 municiou as gestões municipais para a solução de problemas estruturais, a saber: o artigo 23 dispõe que "é competência comum da União, dos Estados, do Distrito Federal e dos Municípios promoverem programas de construção de moradias e a melhoria das condições habitacionais". No capítulo da Política Urbana, o artigo 182, parágrafo 1ำ, estabelece: "O plano diretor, aprovado pela Câmara Municipal, obrigatório para cidades com mais de vinte mil habitantes, é o instrumento básico da política de desenvolvimento e de expansão urbana". 
A partir desse instrumental, os governantes têm mecanismos jurídicos para, se não solucionar, ao menos amenizar um grave problema, que é o de moradia para a população de baixa renda, diminuindo as gritantes desigualdades no acesso ao solo urbano. A Constituição também concedeu amplos poderes ao poder municipal para coibir as especulações imobiliárias e punir os especuladores. Os governantes (membros do executivo e legislativo) podem lançar mão de mecanismos, como taxações progressivas do IPTU, parcelamento ou edificação compulsória e até a desapropriação.

Reza o artigo 182 da Constituição, em seu parágrafo 4으, que é facultado ao Poder Público Municipal, mediante lei específica para área incluída no plano diretor, exigir, nos termos da lei federal, ao proprietário do solo urbano não edificado, subtilizado ou não utilizado, que promova seu adequado aproveitamento, sobpena, sucessivamente, de:

I - Parcelamento ou edificação compulsórios;

II - Imposto sobre propriedade predial e territorial urbana progressivo no tempo;

III - Desapropriação com pagamento mediante títulos da dívida pública de emissão previamente aprovada pelo Senado Federal, com prazos de resgate de até dez anos, em parcelas anuais, iguais e sucessivas, assegurados o valor real de indenização e os juros legais.

Os artigos citados foram regulamentados pelo Estatuto da Cidade (Lei n. 10.257, de julho de 2001), lei que representou um passo importante na formatação de uma política urbana participativa e com controle social. No capítulo da Gestão Democrática, está previsto, no artigo 20 , inciso II, que a política urbana deve ser exercida como "gestão democrática por meio da participação da população e de associações representativas dos vários segmentos da comunidade na formulação, execução e acompanhamento de planos, programas e projetos de desenvolvimento urbano". O capítulo IV, art. 43, prevê que, para garantir a gestão democrática da cidade, deverão ser utilizados, entre outros, os seguintes instrumentos: I - órgãos colegiados de política urbana, nos níveis nacional, estadual e municipal; II-debates, audiências e consultas públicas; III - Conferências sobre assuntos de interesse urbano, nos níveis nacional, estadual e municipal; IV - iniciativa popular de projeto de lei e de planos, programas e projetos de desenvolvimento urbano.

A proposição que permeia a lei é a garantia a todos do "direito de acesso à cidade", a partir das exigências da vida moderna, como acesso à água, esgoto, eletricidade, transporte educação, lazer etc.. Significa estreitamento de laços com a comunidade e a possibilidade de criação de novos mecanismos de participa- 
ção popular. No entanto, a implementação do Estatuto depende dos municípios, por meio da incorporação dos instrumentos nos Planos Diretores elaborados pelas prefeituras e aprovados pelos legislativos. A realidade tem demonstrado extrema resistência na aceitação dos instrumentos, notadamente o IPTU progressivo no tempo. Mesmo com a previsão nos Planos Diretores, os executivos resistem em aplicar a lei.

A criação do Ministério das Cidades, em 2003, significou um ponto de partida importante para todos os segmentos envolvidos com as lutas urbanas, pois, pela primeira vez, tem-se um tratamento integrado de todas as políticas urbanas, na medida em que se superou o recorte setorial da habitação, do saneamento, dos transportes e mobilidade urbana para integrá-los, levando em consideração o uso e a ocupação do solo. A estrutura do Ministério das Cidades foi apontadacomo uma novidade, não só no território brasileiro, mas em toda a América Latina. Sua importância aumenta quando se constata que, no passado recente, as marcas da política urbana foram ausência de planejamento e desarticulação. Por exemplo, no caso da política de habitação, com o fim do Banco Nacional da Habitação (BNH), em 1986, o que se seguiu foi uma constante reformulação no setor, com descontrole nos gastos públicos. Segundo Bonduki (2008), o setor do governo federal responsável pela gestão da política habitacional esteve subordinado a nada menos que sete ministérios ou estruturas administrativas diferentes.

Encontra-se em gestação uma Política Nacional de Desenvolvimento Urbano. Conforme define o texto base do Fórum Nacional pela Reforma Urbana (FNRU) para a II Conferência das Cidades (2005), a proposta da política pressupõe um entendimento do processo de urbanização brasileira, historicamente permeado por distorções propícias a um modelo de acumulação capitalista, centrado na desigualdade e que se transforma em mecanismos de "espoliação urbana". A nova política deve, necessariamente, garantir a superação dos desequilíbrios em diferentes patamares e permitir o acesso à cidade, levando-se em conta as especificidades de gênero, raça, etnia e de classe. A novidade no processo está não se tratar de uma proposição de política pública de uma única via, a via do Estado, pois o diálogo com os movimentos sociais e a sociedade, de maneira geral, flui, ainda que de maneira tensa, por meio do mecanismo das Conferências das Cidades, nos diversos níveis, e do próprio Conselho das Cidades.

Um divisor de águas na luta por moradias de interesse social foi a aprovação pelo Senado, em 2005, do Projeto de Lei 2710/92, de iniciativa popular, que criou o Sistema Nacional de Habitação de Interesse Popular. O projeto transformou-se na Lei Federal 11.124/05, que instituiu o Sistema e o Fundo Nacional de Habitação de Interesse Social (SNHIS/ FNHIS) e seu Conselho Gestor, criando as condições legais e institucionais para a consolidação do setor habitacional como política de Estado. Esse projeto tramitou por 14 anos, 
mas, apesar da demora, significou uma vitória, pois, segundo Fleury (2007), vigorou "o entendimento de que o projeto originado de iniciativa popular constituiria exceção ao princípio de reserva de iniciativa do Chefe do Poder Executivo, sendo o projeto sancionado pelo Presidente da República".

Já como resultado do novo sistema, a Secretaria Nacional de Habitação estruturou o Plano Nacional da Habitação (PlanHab). O PlanHab vem a se somar a um conjunto de ações e medidas de natureza institucional, econômica e jurídica, que têm por objetivo dar corpo e consistência ao Sistema Nacional de Habitação. No ano de 2007, ocorreu a adesão de Estados e Municípios ao SNHIS. A adesão é condição necessária para o fortalecimento da nova organização institucional do setor, tendo como compromissoa elaboração de seus Planos de Habitação de Interesse Social, além da constituição do Fundo de Habitação de Interesse Social e de seu Conselho Gestor.

Os dados quantitativos e qualitativos reunidos sobre as necessidades habitacionais apontam que os deficit mais expressivos concentram-se cada vez mais nas áreas urbanas e nas faixas mais baixas de renda da população, estando localizadas, principalmente, nas regiões metropolitanas. Tomando por base a metodologia desenvolvida pela Fundação João Pinheiro, o deficit habitacional brasileiro em 2008 era de 5,546 milhões, sendo 83,5\% de área urbana (BRASIL. MINISTÉRIO DAS CIDADES, 2011)

A qualidade das moradias existentes para a população com essa faixa de renda apresenta inúmeras deficiências: algum tipo de carência de padrão construtivo, situação fundiária, acesso aos serviços e equipamentos urbanos, entre outros. A ausência de infraestrutura urbana e saneamento ambiental é o maior problema; envolve 10,2 milhões de moradias, ou seja, 32,1\% do total de domicílios urbanos duráveis do País têm pelo menos uma carência de infraestrutura (água, esgoto, coleta de lixo e energia elétrica), sendo 60,3\% nas faixas de renda de até 3 salários mínimos.

O PlanHab tem como meta de planejamento o ano de 2023, com suas revisões correspondentes aos anos de elaboração dos Planos Plurianuais (PPA's): 2011, 2015 e 2019. A elaboração do Plano Nacional de Habitação envolve três etapas: a contextualização, a elaboração de cenários e metas e a definição do plano de ação, estratégias e implementação. São pressupostos do Plano a garantia à moradia digna como direito universal e fator de inclusão social e a gestão democrática e participativa da política habitacional (Ministério das Cidades, 2004). Os planos devem ser direcionados prioritariamente para atender a população de faixa de renda entre zero e três salários mínimos. Os princípios que embasam a construção dos Planos Municipais de Habitação de Interesse Social são: 1) A garantia à moradia digna como direito universal e fator de inclusão social; 2) a 
garantia da função social da cidade e da propriedade; 3) a gestão democrática e participativa da política habitacional; 4) o reconhecimento da existência de demandas específicas e diferenciadas (idosos, portadores de deficiência, crianças e gênero); 5) o respeito às identidades culturais e fortalecimento dos vínculos familiares e comunitários já existentes.

A implementação das etapas do Plano demanda grande comprometimento do nível municipal em pactuar com a sociedade a hierarquia de prioridades. Há, ainda, um constrangimento institucional não desprezível, que limita as iniciativas vinculadas ao Ministério das Cidades, o agente operador. O principal agente operador dos recursos do FGTS, a Caixa Econômica Federal, é subordinado ao Ministério da Fazenda. Conforme aponta Bonduki (2008), a Caixa possui enormecapilaridade; está presente em todos os municípios do País e dispõe de regras e programas em curso que desenham a política habitacional sob sua responsabilidade. As regras e programas seguem a lógica do sistema bancário; consideram a capacidade de pagamento (e consequente comprovação de renda) para aprovar financiamentos, o que se apresenta como um empecilho no atendimento das necessidades da população de menor renda.

Para o caso do saneamento básico, foi construído o Plano Nacional de Saneamento Básico - PLANSAB, Lei Nacional do Saneamento Básico (Lei no. 11.445, de 5 de janeiro de 2007). As previsões e metas apontam para: a) definição de objetivos e metas nacionais e regionalizadas e o engajamento de todos os entes federados pela universalização do saneamento básico nas áreas urbana e rural; b) superação das desigualdades e inclusão social por meio da universalização do saneamento básico - em abastecimento de água potável, esgotamento sanitário, manejo de resíduos sólidos e manejo de águas pluviais - que deve garantir, independentemente de classe social e capacidade de pagamento - qualidade, integralidade, continuidade, inclusão social e, ainda, contribuir para a superação das diferentes formas de desigualdades sociais e regionais, em especial as desigualdades de gênero e étnico-raciais; c) cumprimento de metas no sentido de reduzir à metade, até 2015 , o número de pessoas sem acesso ao abastecimento de água e ao esgotamento sanitário (Ministério das Cidades, 2008).

Em 2007, ocorreu a implantação do Programa de Aceleração do Crescimento (PAC). O argumento central para suas dimensões estava na necessidade de dinamizar a economia com uma série de investimentos em infraestrutura (energia, rodovias, saneamento básico, habitação). Saneamento e habitação (urbanização de assentamentos precários) foram os itens privilegiados; recursos foram sendo repassados a estados e municípios.

Já o ano de 2009 foi inaugurado com o impacto da crise financeira global e sob a expectativa dos seus reflexos no Brasil. O presidente Lula, utilizando largamente 
2. Segundo a autora, as cidades, à medida que cresciam e atraiam pessoas de fora, foram criando mecanismos de exclusão social, diferentes a cada época, mas num continuum baseado na oposição cidade legal/ cidade clandestina. A cidade não legalizada localiza-se nos bairros periféricos, nos morros, fundo de vales, terrenos sem regularização fundiária etc.. o artifício de tentar traduzir para a linguagem popular assuntos de interesse nacional, afirmou que a onda gigantesca de desestabilização das economias centrais atingir-nos-ia como "uma marolinha". Medidas para manter a economia aquecida foram tomadas; uma destas, que diz respeito ao tema deste artigo, foi o Programa "Minha Casa, Minha Vida", consolidado pela Lei n. 11.977, de 7 de julho de 2009. A previsão foi de recursos provenientes do Fundo de Arrendamento Social e do Fundo de Desenvolvimento Social, correspondendo respectivamente a 14 bilhões de reais e 500 milhões de reais, ambos geridos pela Caixa Econômica Federal. A iniciativa governamental estaria canalizando recursos para dinamizar a economia a partir do setor da construção civil, capaz de grande absorção de mão de obra e de estimulação de setores econômicos correlatos. A centralidade passa a ser das empresas que apresentam projetos diretamente à CEF, para avaliação e aprovação. O controle do Programa passa a ser feito pelo mercado, não atendendo as necessidades da população interessada. O foco principal das empresas é o lucro, e não o atendimento da população, tendo por critério os mais necessitados como estava previsto no PLNHIS. A situação agrava-se diante da ausência de estoques de terras a baixo custo nos municípios, principalmente os de grandes centros e áreas metropolitanas. A expectativa é que a população que habita a "cidade clandestina" para, usarmos os termos de Rolnik (1990)² , continuará a ser preterida em relação à lógica de mercado.

\section{Os espaços da democracia deliberativa}

Passados mais de 20 anos de aplicação dos preceitos embutidos no texto constitucional, cabe fazer um balanço da participação popular no campo da política urbana, bem como refletir em torno da construção da democracia no Brasil, levando em conta as possibilidades de implementação da democracia deliberativa e os limites da democracia representativa.

Um tema recorrente diante das novas práticas é o que aponta os limites da democracia representativa e as discussões que indicam as possibilidades de ampliação da participação democrática. Diversos autores têm trabalhado com a temática à luz de experiências recentes, notadamente as que têm como palco os países em desenvolvimento na América Latina, Ásia e África. Santos (1999), por exemplo, reúne uma série de estudos focados em práticas desenvolvidas em Moçambique, na Índia e no Brasil. A temática tem recebido diversas denominações como democracia participativa (BENEVIDES, 1994; GIDDENS, 2005), democracia semidireta (SANTOS, 1999), democracia deliberativa (FUNGERIK e WRIGHT, 2000), entre outras.

As experiências vivenciadas em diferentes partes do mundo geram possibilida- 
des um tanto quanto diferenciadas para a busca de superação do modelo de democracia liberal representativa. Modelo esse marcado por inúmeras insatisfações e limitações fartamente elencadas na bibliografia sobre o tema. Quando as reflexões têm como mira a realidade brasileira, o quadro consolidado que se forma do modelo hegemônico é o de uma inclusão política abstrata, plantada em meio a uma, ainda, concreta exclusão social. Nas sociedades ocidentais, os princípios de igualdade, liberdade e cidadania são formalmente reconhecidos como princípios emancipatórios da vida social. No entanto, na sociedade brasileira, vigoram os princípios de desigualdade e exclusão como forma de regulação social. $\mathrm{O}$ acesso a bens e direitos ocorre de diferentes formas, dependendo do grupo social a que se está vinculado. Particularmente, o racismo e sexismo são dispositivos de hierarquização que combinam desigualdade e exclusão. Para as mulheres, o princípio da exclusão manifesta-se na distinção entre o público e o privado e no princípio da integração desigual, representado por sua participação em formas desvalorizadas da força de trabalho. Segundo Santos, houve uma "sexização da força de trabalho" (SANTOS, 2006, p. 281). No caso do racismo, a exclusão manifesta-se na hierarquização das raças, na integração desigual e, também, no acesso a formas desvalorizadas de postos no mercado de trabalho.

Inúmeros são os esforços e iniciativas que buscam a ampla inclusão econômica, política e cultural de grupos fragilizados. Ao longo dos anos 1990, aprofundou-se o processo de democratização brasileiro. Ao lado da construção de instituições democráticas (eleições livres, parlamento ativo, liberdade de imprensa, amplo espectro partidário), a vigência da plena democracia pressupõe que as "práticas cotidianas" sejam permeadas pelos valores democráticos. Por isso, a análise dos processos sociais ocorridos na democratização não pode se limitar à esfera institucional; precisa verificar transformações moleculares no tecido social e na cultura política. Entende-se, conforme Avritzer, que "a democratização não é um período de transição, é o processo permanente e nunca inteiramente acabado de concretização da soberania popular" (AVRITZER, 2004, p. 2).

No entanto, é preciso não alimentar ilusões de um caminho fácil de exercício pleno da soberania popular. Pelas regras da democracia representativa, a inclusão de grupos anteriormente excluídos implica que alguns segmentos percam poder ou, ao menos, sofram uma redução em seu controle social. Nesses termos, a democracia representativa nos moldes liberais tende a ser hegemônica, pois é o formato que interessa às elites, mas continuará a ter um perfil de fragilidade, já que não completa o que Young prescreve: "em uma sociedade de massa, para que a política seja realmente democrática, a representação e a participação exigem uma reciprocidade permanente" (YOUNG, 2000, p. 124). A introjeção de maior justiça no escopo da representação tem sido objeto de debate intenso nos últimos anos diante da proposição de "cotas" para segmentos, como é o 
caso de reserva de vagas para mulheres candidatas no interior dos partidos.

É fato que as duas últimas décadas de prática democrática registraram a expansão de novos formatos participativos por todo o território nacional. Esses formatos materializaram-se em experiências diversificadas, como os mais de 27 mil conselhos gestores de políticas públicas em nível municipal, estadual e federal; os vários fóruns do orçamento participativo; as inúmeras conferências por áreas específicas; as experiências com os formatos de consulta popular (referendos e plebiscitos), entre outras. Tal disseminação ocorreu não apenas nos centros mais desenvolvidos,com tradição de luta popular, já que houve uma interiorização dessas experiências. Em paralelo, o interesse crescente pelo assunto gerou uma quantidade significativa de trabalhos acadêmicos que tratam ora da efetividade dos. Conselhos e Fóruns; ora de sua pouca eficácia e legitimidade. Essa rede tecida de novas práticas coloca questões que apontam para o redimensionamento das relações entre sociedade civil e Estado.

Apesar da intensidade participativa de hoje, detectam-se inúmeros problemas limitadores da prática democrática. Constata-se, principalmente, que o que ocorre no espaço da democracia participativa não tem peso suficiente para modificar práticas e agendas do espaço da democracia representativa. Em paralelo às frustrações, viu-se desgastar a confiança dos cidadãos em relação aos mecanismos e agentes democráticos: partidos, Congresso e políticos. Trata-se de um fenômeno mais amplo.

Como contraponto, é no nível local que as práticas participativas têm alcançado maior intensidade, com o envolvimento de grande número de pessoas em conselhos, fóruns e conferências. De forma inversamente proporcional, as Câmaras Municipais reproduzem práticas da velha política do clientelismo e troca de favores, a ponto de não conseguirem justificar sua função junto à população.

Diante dessas questões, entende-se que o acúmulo de experiências participativas terá significado para a garantia de manutenção e ampliação dos espaços de intervenção e para superar a dicotomia entre democracia formal e inclusão social. Em paralelo ao modelo hegemônico, multiplicam-se as experiências de democracia participativa ou democracia popular, que têm como protagonistas grupos sociais subalternos, organizados em movimentos sociais, e agentes que se encontram atuando na esfera estatal, cuja proposta política é a de facilitar a superação do modelo vigente.

O que aparecia com maior destaque para o caso brasileiro, e que se tornou o carro-chefe da divulgação de práticas bem-sucedidas de participação popular, foi o formato do Orçamento Participativo, que ganhou visibilidade em 
Porto Alegre, na gestão do Partido dos Trabalhadores (PT), mas são inúmeros e diversificados os fóruns que preveem a participação popular. Os Conselhos Gestores de Políticas Públicas constituem-se em outro exemplo que pressupõe um formato participativo includente. Pode-se afirmar que hoje existem canais e mecanismos adequados para que ocorra o controle democrático por parte da sociedade. O quadro apresentado chama ao debate a questão teórica da relação Estado-sociedade.Há uma tradição analítica predominante, que contrapõe Estado e sociedade, como se o primeiro fosse o foco de todo o mal; e a segunda, o polo da virtude. Existe um esforço analítico de vários autores, baseados em práticas políticas recentes, em oferecer uma leitura dessa relação menos demonizada (DAGNINO, 2002; LAVALLE, 2003; DAGNINO, OLVERA e PANFICHI, 2006; MOURA e SILVA, 2008). Um equívoco é analisar o polo sociedade como homogêneo, desconsiderando que este apresenta práticas e concepções heterogêneas e está atravessado por interesses e tensões. São múltiplos os sujeitos, tanto do campo progressista quanto do campo conservador, que se manifestam também em espaços diversos e multifacetados. São associações de classe, sindicatos de trabalhadores e patronais, conselhos, fóruns, redes de movimentos vinculados a lutas espacializadas (como bairros, conjuntos habitacionais) ou temáticos (como mulheres e negros) etc.. Nesses espaços, estão em disputa projetos políticos distintos. Segundo Dagnino (2002), os projetos apontam em direções opostas e até antagônicas, mas reivindicam a mesma sociedade civil participativa e propositiva. Há que se reconhecer, ainda, outros agentes que atuam como mecanismo de controle: Ministério Público e imprensa.

A complexidade e os avanços verificados no campo das políticas públicas urbanas permitem pensar na estruturação, ao longo dos anos, de redes sociais dando sustentabilidade ao sistema. Moura e Silva (2008) propõem a análise de redes sociais (ARS), "tema que passou a fazer parte da pauta metodológica dos estudos sobre organizações, movimentos sociais, participação e gestão pública, bem como das inovações institucionais a eles associadas" (MOURA e SILVA, 2008, p. 44).

A abordagem em rede caminha no sentido de apreender diferentes padrões de relação entre Estado e agentes não estatais. Esse campo de estudos apresenta-se dinâmico à medida que permite visualizar tanto alianças constituídas entre os segmentos estatais e não estatais quanto entre grupos de um mesmo segmento. Além disso, os anos de prática democrática foram pontuados por extrema circulação de indivíduos. Muitas lideranças foram forjadas no calor das lutas populares das décadas de 1970 e 1980 e passaram a ocupar cargos eletivos nos diferentes níveis de poder - vereadores, prefeitos, deputados - e também nas estruturas administrativas dos executivos.

Entende-se, por outro lado, que está em processo a formatação da esfera pública 
democrática no Brasil e a ocupação dos espaços públicos por sujeitos sociais e políticos que sejam capazes de formular e publicizar as suas demandas. Isso é central nessaformatação.OConselhodasCidadeseasConferênciasdasCidadesdespontam como espaços legítimos de expressão e de articulação em torno da política urbana.

\section{As Conferências das Cidades}

A 1aㅡ Conferência Nacional das Cidades foi convocada por meio de decreto presidencial, de 22 de maio de 2003, e foi coordenada pelo novo Ministério das Cidades. A fase preparatória da Conferência foi composta por diversas etapas. A primeira previa as conferências municipais, nas quais seriam eleitos os delegados para cada Conferência Estadual, que, por sua vez, desencadearia o processo de eleição de delegados para participar da Conferência Nacional. Apesar do reconhecimento das boas intenções do Ministério das Cidades, inúmeros governos locais e entidades não governamentais envolvidas com a questão urbana consideraram o tempo para a realização das diversas etapas muito escasso, para garantir uma ampla participação popular nas discussões e no levantamento dos problemas urbanos.

Como alternativa às Conferências das Cidades, realizadas nos vários níveis de poder, em período de tempo muito curto e sem o envolvimento da população nos debates, diversas cidades tomaram a iniciativa de realizar o "Congresso das Cidades". Diferentes localidades como Campinas, Porto Alegre, Belém, Santo André, Maringá e Vitória realizaram seu "Congresso da Cidade". Todos os eventos tiveram como características extrapolar o apertado calendário oficial e desencadear um amplo processo de participação.

Apesar das críticas ao exíguo tempo para as etapas preparatórias, a 1a Conferência Nacional das Cidades reuniu representantes de mais de 3 mil municípios, analisou e votou em torno de 1,2 mil propostas oriundas das conferências municipais e estaduais. Novas propostas para o desenvolvimento urbano foram produzidas. O plenário estabeleceu a sua composição e elegeu os membros do Conselho Nacional das Cidades (Concidades). Participaram da Conferência 2,095 mil delegados, assim distribuídos: 928 administradores públicos e legisladores e 1167 representantes da sociedade civil, a saber: 541 militantes de movimentos sociais e populares; 203 representantes de entidades sindicais de trabalhadores; 190 delegados de ONGs e entidades profissionais, acadêmicas e de pesquisa; 153 representantes de empresários relacionados à produção e ao financiamento do desenvolvimento urbano; e 80 outros participantes.

O relatório final da Conferência traz uma leitura das principais questões que afligem a sociedade brasileira a partir da dinâmica urbana. São questões fundantes 
do documento a universalização do acesso à terra urbana e à moradia digna, ao saneamento ambiental, à água potável, ao trânsito seguro e ao ambiente saudável. O controle social e o tema da participação nas tomadas de decisões aparecem no documento, norteando os procedimentos referentes às políticas urbanas. A preocupação com a inclusão de grupos étnicos e raciais, das mulheres e da população de baixa renda aparece com destaque nas resoluções. Enfim, o documento aponta que o direito à moradia digna pressupõe uma teia complexa de ações, tanto de governos quanto da sociedade organizada.

As atividades de preparação para a 2a Conferência das Cidades, realizada no início de dezembro de 2005, permitiu aque os municípios e estados dispusessem de mais tempo de preparação. Muitos entes desencadearam discussões locais e preparatórias para cumprir as etapas. A pauta de discussões versou sobre as seguintes temáticas: I. Participação e Controle Social; II. Questão Federativa; III. Política Urbana Regional e Metropolitana; IV. Financiamento e Desenvolvimento Urbano.

No entanto, a participação ficou aquém do esperado; nenhum segmento preencheu a cota de delegados. Compareceram 1,820 mil delegados, distribuídos em: 668 administradores públicos e legisladores; 74 representantes de ONGs; 561 representantes de movimentos populares; 89 profissionais, acadêmicos e pesquisadores; 180 representantes de trabalhadores; 156 representantes do empresariado; 21 conselhos de classe; e 71 membros do Conselho Nacional das Cidades.

A 2a Conferência Nacional das Cidades retomou várias das propostas não implementadas desde a 1a Conferência e aprofundou a análise de inúmeros pontos da Política Nacional de Desenvolvimento Urbano, no caminho da construção da democracia participativa. O ponto 14 do documento final indica caminhos essenciais para a concretização da democracia participativa e delibera que o Ministério das Cidades garanta:

a) a criação dos conselhos das cidades nos municípios, no prazo máximo de um ano;

b) a dotação orçamentária nos três níveis de governo, para viabilizar, financeiramente, a participação dos conselheiros dos segmentos Movimento Popular, ONGs e trabalhadores;

c) o caráter deliberativo do ConCidades (garantido por lei);

d) a capacitação dos conselheiros;

e) a parceria com os governos locais e o Ministério Público; 
f) a divulgação das ações do Conselho Nacional das Cidades.

O caráter deliberativo do ConCidades, garantido por lei, sobressai a todas as outras medidas de urgência. Por mais que o Executivo acate as resoluções do Conselho, seu caráter deliberativo é o que garantirá a efetividade das medidas, havendo, então, a prevenção contra as turbulências políticas conjunturais. As ações previstasvoltadas para os conselheiros, como a capacitação e a viabilização financeira para garantir a participação de segmentos da sociedade civil, são fundamentais.

Esse olhar atento e qualificado pode significar um ganho importante para o futuro das políticas urbanas, já que uma das críticas centrais, principalmente no campo das políticas sociais no Brasil, é, ano após ano, a descontinuidade de propostas, a sobreposição de programas e descontrole de gastos. Com o acompanhamento rigoroso de segmentos interessados, tanto da sociedade quanto de representantes governamentais, principalmente os municipais, pode-se conjecturar a instalação de um sistema nacional de política urbana mais coerente.

A 3ạ Conferência Nacional das Cidades ocorreu em novembro de 2007 por empenho decisivo dos conselheiros do Conselho Nacional das Cidades. Em 2006, houve um rearranjo político emergencial levado a cabo pelo Palácio do Planalto, por conta de crise política, que entregou o Ministério das Cidades a um partido da base aliada. O ministro anterior, Olívio Dutra (PT), pertencente ao partido do Presidente da República e um dos responsáveis pelo desenho que a política urbana vinha assumindo até então, foi substituído por político de perfil conservador, vinculado ao Partido Progressista (PP).

A 3a Conferência, que teve como tema "avançando na construção democrática das cidades", reuniu em Brasília 2,513 mil pessoas, sendo 2,040 mil delegados, representando 3,277 mil municípios, os 26 estados da federação, mais o Distrito Federal. As teses foram debatidas ao longo do ano nas conferências municipais e estaduais, encarregadas, também, da indicação de delegados representantes de vários segmentos. Nessa etapa preparatória, 16,151 mil pessoas participaram das assembleias, segundo o Relatório Final da 3a Conferência Nacional das Cidades (Ministério das Cidades, 2008).

Foram 136 propostas aprovadas nas plenárias, divididas em seis eixos: I As intervenções urbanas e a integração de políticas; II - As intervenções urbanas e o controle social; III - As intervenções urbanas e os recursos; IV - Capacidade Administrativa e Estrutura Institucional; V - Receitas municipais e ampliação de receitas próprias; VI - Sistema nacional de desenvolvimento urbano. Permeou as discussões e as propostas apresentadas a necessidade de integrar as políticas urbanas das três esferas de governo 
para garantir a otimização de recursos e dos resultados. Tal integração teve que ocorrer também entre as políticas intersetoriais, nas áreas econômica, social e ambiental. A democratização de acesso a recursos foi outro ponto forte nas discussões, ficando deliberada a garantia de acesso das entidades sociais aos diversos fundos de fomento disponíveis: Fundo de Amparo ao Trabalhador (FAT), Fundo Nacional de Habitação de Interesse Social (FNHIS), Orçamento Geral da União (OGU) e outros.

O controle social passa pela garantia de dotar o Conselho das Cidades de caráter deliberativo. Esse tema, que se arrasta desde a 1a Conferência, retornou como ponto central no terceiro encontro, quando se estabeleceu um prazo de 180 dias para que o governo federal encaminhasse ao legislativo projeto de lei para regulamentar o assunto. Apontou-se para a necessidade de o controle social ser fortalecido por meio da criação de conselhos municipais e estaduais das cidades.

Tabela 1 - Representação por segmento nas Conferências das Cidades

\begin{tabular}{|l|l|l|l|}
\hline Segmento & I & II & III \\
\hline PPM & 390 & 354 & 367 \\
\hline PPE & 232 & 167 & 200 \\
\hline PPF & 189 & 147 & 137 \\
\hline Concessionárias Púplicas e Privadas & 197 & - & - \\
\hline Movimentos Populares & 541 & 561 & 695 \\
\hline Trabalhadores & 203 & 180 & 219 \\
\hline Empresários & 153 & 156 & 187 \\
\hline Entidades Acadêmicas & $*$ & 89 & 145 \\
\hline Conselhos de Classe & - & 21 & - \\
\hline ONGs & 190 & 74 & 90 \\
\hline Conselho das cidades & - & 71 & - \\
\hline Total & 2.095 & 1.820 & 2.040 \\
\hline
\end{tabular}

Fonte: www.cidades.gov.br/conselho-das-cidades/conferências-das-cidades

*ONGs e entidades acadêmicas formaram um único segmento

Os segmentos governamentais representados nas conferências - Poder Público Municipal (PPM), Poder Público Estadual (PPE) e Poder Público Federal (PPF) tiveram suas representações de executivo e legislativo reunidas. A análise dos 
3. O Decreto foi substituído pelo de número 5.790, de 26 de maio de 2006 . dados de representação por segmentos nas três conferências posiciona-nos quanto ao vigor da representação da sociedade civil e mais incisivamente do segmento movimentos populares. Nos três encontros, os representantes somaram sozinhos mais de um quarto do total de delegados. As vagas disponíveis para todos os segmentos nunca foram ocupadas em sua totalidade. À guisa de exemplo, temos a 2a Conferência: para o segmento dos empresários, havia disponíveis 249 vagas, foram ocupadas apenas 156, ou 62,6\% do total; para o segmento movimentos populares, havia disponíveis 669 vagas, foram ocupadas 561, ou $83 \%$ do total. Some-se à análise o fato de que os integrantes do segmento apresentam maiores dificuldades materiais de ausentarem-se de suas localidades, ainda que o poder público financie-os, por deliberação do Conselho das Cidades.

A 4ạ Conferência das Cidades, em 2010, teve, à frente de sua organização, o Conselho das Cidades. A opção foi a de se realizar um balanço dos desafios e entraves na efetivação das políticas urbanas. Os quatro eixos temáticos foram: criação e implementação de conselhos das Cidades, planos, fundos e seus respectivos conselhos nas esferas federal, estadual, municipal e Distrito Federal; aplicação do Estatuto da Cidade, dos planos diretores e a efetivação da função social da propriedade do solo urbano; a integração da política urbana no território: política fundiária, mobilidade e acessibilidade urbana, habitação e saneamento; a relação entre os programas governamentais - como o PAC e Minha Casa, Minha Vida - e a política de desenvolvimento Urbano.

Os eixos temáticos apontam para a necessidade de aprofundamento das discussões quanto aos avanços e limites da política urbana. As leis e programas de caráter nacional estão estruturados e têm por base o debate com a sociedade, o controle social, e a integração com os fóruns da democracia deliberativa. Entretanto, a operacionalização deixa a desejar, pois os que mais urgentemente precisam ser incorporados e ter garantidos seus direitos de cidadania não são ouvidos. Além disso, é recorrente a detecção de práticas clientelistas e de tráfico de influência em uma política que envolve consideráveis volumes de recursos.

\section{O Conselho das Cidades}

O ConCidades nasceu como uma promessa de se tornar uma prática inovadora no campo participativo, já que apresenta uma verticalização importante de abertura de participação da sociedade organizada no nível decisório federal. Refere-se, especificamente, ao formato amplo dado ao ConCidades e às articulações em todos os níveis de preparação das Conferências das Cidades, em suas etapas municipal e estadual. O Decreto Presidencial no. 5.031, de 02 de abril de 2004, dispôs sobre a composição, estruturação, competências e funcionamento 
do ConCidades ${ }^{3}$.

A 2a Conferência Nacional das Cidades alterou a composição do Conselho de 70 para 86 membros, passando a representação dos gestores para 37, divididos em 17 membros do poder público federal, 9 membros do poder público estadual e 11 membros do poder público municipal. A representação da sociedade passou a contar com 49 membros, divididos em 23 representantes dos movimentos sociais e populares, 8 membros das entidades empresariais, 8 membros das entidades dos trabalhadores, 6 das entidades acadêmicas e 4 das organizações não governamentais. Atualmente, o ConCidades é constituído por 86 titulares: 49 representantes de segmentos da sociedade civil e 37 dos poderes públicos federal, estadual e municipal - além de 86 suplentes, com mandato de dois anos. A composição do ConCidades inclui, ainda, 9 observadores, representantes dos governos estaduais que possuírem Conselho das Cidades em sua respectiva unidade da federação.

Para avaliar a positividade do formato do ConCidades, usou-se como parâmetro a análise que Pinto (2004) faz de dois outros conselhos criados no governo Lula: o Conselho de Desenvolvimento Econômico e Social (CDES) e o Conselho Nacional de Segurança Alimentar (Consea). A autora não se propõe avaliar o desempenho ou a validade dos conselhos, mas os estuda a partir da perspectiva da participação da sociedade civil e, ainda, utiliza o Conselho Nacional da Assistência Social, "mais antigo e institucionalizado", como o seu contraponto de análise. A autora aponta, acertadamente, que o Consea divide com o CDES a mesma característica, de ser um conselho com membros designados pelo Presidente da República sem prever nenhuma consulta prévia. É bastante interessante a forma como está redigido o decreto, pois a sociedade civil será representada por pessoas não por ela designadas. A ideia de representação não é levada em consideração; a sociedade civil passa a ser representada por "personalidades" na leitura do Executivo Federal. Na representação governamental, a diferenciação do ConCidades em relação aos três outros está na participação de representantes dos poderes público estadual e municipal.

No que se refere à participação da sociedade civil, conforme apontado por Pinto (2004), no CDES e no Consea há a presença de "personalidades" indicadas pelo Executivo Federal, a partir do entendimento de que estariam representando setores expressivos desse segmento. Registre-se, ainda, a presença de segmentos ligados às Igrejas. O CNAS é um Conselho já consolidado, com representações tradicionais de ONGs, profissionais do segmento e representantes da Igreja.

O desafio persiste: o ConCidades, que não possui caráter deliberativo, é, ainda, uma política de governo e não de Estado. As suas atribuições e composição, garantidas por Lei Federal, são uma reivindicação central, já discutida na 
4. As resoluções estão disponíveis no site www.cidades. gov.br. Acesso em 23/03/2009.

5. O Ministério das Cidades acatou a recomendação e, por meio da Portaria no 462 de 24/09/ 2008, constituiu um Grupo de Trabalho Interministerial (GTI) para estruturar o projeto estratégico de elaboração do Plano, composto pelos seguintes órgãos: Ministério do Meio Ambiente, Agência Nacional de Águas, Ministério da Saúde, Fundação Nacional de Saúde, Ministério da Integração Nacional e todas as secretarias do Ministério das Cidades, sob a coordenação da Secretaria Nacional de Saneamento Ambiental.

6. Estados que possuem Conselhos das Cidades: Bahia, Maranhão, Minas Gerais, Mato Grosso do Sul, Paraná, Pará, Rio de Janeiro, Rio Grande do Sul, Piauí, Roraima, Tocantins e Pará. Fonte: FNRU, citado em Nascimento, Santos Jr. e Ferreira (2008). 2a - Conferência das Cidades e enfatizada na 3ạ , conforme destacamos. Diante desse formato legal, as decisões tomadas em seu interior têm pouco impacto político-administrativo, caso não ocorra o encaminhamento das deliberações pelo Ministério das Cidades.

Ao se analisar as resoluções do ConCidades, observou-se que havia uma maior quantidade de resoluções que tratava de assuntos de responsabilidade de outros órgãos da administração ou em tramitação no legislativo. Alguns exemplos: apoio a anteprojeto de Lei da Política Nacional de Saneamento Ambiental (Res. 05/2004); apoio à implantação de um pacto federativo visando a redução dos custos do transporte coletivo urbano e o barateamento de tarifas (Res. 06/2004); apoio ao anteprojeto de lei da política Nacional de Saneamento(Res. 22/2004); recomendação ao Congresso Nacional e ao Conselho Curador do FGTS para que impeçam mudanças propostas à destinação de recursos do FGTS (Res. 09/2004); recomendação ao Senado para a aprovação do PL 2710/92 (Res. 10/2004); recomendação para a participação do Ministério das Cidades no Conselho Monetário Nacional (Res. 14/2004) ${ }^{4}$; recomendação ao Ministério do Planejamento a suplementação de orçamentária para destinação de recursos ao Fundo Nacional de Habitação de Interesse social (Res. 32/2005); estabelecimento de prazos e instituição de um Grupo de Acompanhamento, a fim de

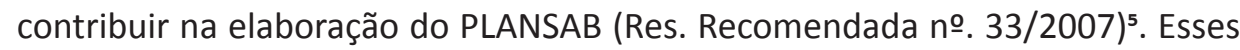
são apenas alguns exemplos de conteúdos das resoluções emitidas. O conseIho só pode "recomendar", "solicitar" "apoiar". Verbos que diferem de "deliberar", "vetar", "fiscalizar", "determinar", que expressariam a capacidade efetiva de elaboração/fiscalização de políticas. As decisões tomadas em plenário, na maioria dos casos, foram de proposições ao Ministério das Cidades, expressões de princípios e de compromissos de ação do ConCidades, proposições a outros órgãos da administração pública e do legislativo (TONELLA, 2009). O ConCidades assume a relevância de seu papel político ao articular as demandas da sociedade e das políticas de gestão urbana. Outra dimensão que não deve ser desprezada é que ocorreram avanços na constituição dos conselhos estaduais das cidades. Em 2007, existiam apenas sete; em 2008, o número passou para dez $z^{6}$.

\section{A Visibilidade das Entidades da Sociedade Civil}

A emergência dos movimentos populares na década de 1980, no cenário brasileiro, em contexto da luta pelo fim do regime militar, foi celebrado pela academia e gerou inúmeras análises. Textos fundamentais, como o de Sader (1988), que apontavam a "entrada em cena" dos novos atores, referenciaram uma vasta produção bibliográfica. Com o processo de ampliação da participação democrática e a consequente abertura de canais institucionais de diálogo e negociação 
com os órgãos públicos, a década seguinte foi entendida pelos analistas como de refluxo dos movimentos de massa e populares em nome da utilização de canais institucionalizados.

O projeto "democrático popular", construído ao longo de mais de vinte anos, teve, no Partido dos Trabalhadores (PT), seu expoente no que diz respeito à articulação entre os movimentos sociais, as demandas da população e a política partidária. Revisitando antigos textos de Sader (1983), verifica-se que, nas primeiras eleições em que o partido participou, em 1982, a ideia generalizada era a de que o PT seria a expressão dos movimentos sociais, não pretendendo ir além disso. Haveria uma identificação entre "vontade popular" e "proposta política". A proposta do partido seria, de forma direta, a manifestação da vontade popular (SADER, 1983, p. 98). Apesar de aquele momento ser propício para ondas de otimismo e de definições, o autor já apontava para um cenário mais complexo, cuja solução não cabia em receitas simplistas. De qualquer forma, elementos desse projeto foram incorporados à plataforma de ação do governo petista. Ao assumir a presidência em 2002, Lula e sua equipe passaram a estimular a ampliação do formato participativo já consolidado na experiência municipal. Em vários documentos, há referência a uma reformulação da relação entre Estado e sociedade, fortalecendo a democracia. Afirmam também que o governo brasileiro optou por dois caminhos: gestão participativa e uma repactuação entre o governo federal, os estados e os municípios.

Lavalle, Castello e Bichir (2004, p. 35) chamam a atenção ao "misterioso sumiço no debate acadêmico ocorrido nos anos 1990" dos movimentos sociais. A perspectiva dos autores é que os movimentos sociais permaneceram em cena, mas as lentes dos analistas dirigiram-se a outros focos. Apontam que os movimentos sociais continuaram a ocupar posições centrais "nas teias de relações que articulam atores da sociedade civil" (LAVALLE, CASTELLO e BICHIR, 2004, p. 43). Sem dúvidas, ocorreram mudanças ao longo dos anos. Os movimentos com organização no nível nacional são os principais protagonistas do novo cenário. São exemplos: o Movimento dos Trabalhadores Sem Terra (MST), a Central de Movimentos Populares (CMP), o Movimento Nacional de Luta por Moradia (MNLM), a Confederação Nacional das Associações de Moradores (Conam).

Para efeitos deste artigo, apresentaremos um perfil da CMP, do Conam e do MNLM. A Central de Movimentos Populares tem suas origens em 1980, no bojo da Articulação Nacional dos Movimentos Populares e Sindicais (ANAMPOS). No final da década de 1980, em seu 80 Congresso, a ANAMPOS foi dissolvida, dando lugar à Comissão pró-Central de Movimentos Populares. Em outubro de 1993, foi realizado o Congresso de fundação da CMP. Em março de 1996, a Central de 
7.Informações contidas no site do movimento: www. unmp.org.br. Acesso em $12 / 09 / 08$.
Movimentos Populares realizou o seu I Congresso, ocasião em que foram definidas a organização política, as atividades e a estrutura da entidade, sendo eleitas a Coordenação Nacional, Executiva Nacional e Secretarias. Foi definido que os Congressos, como instância máxima da CMP, seriam realizados a cada três anos, com o objetivo de definir um plano de lutas, a linha política e as ações (estratégicas e táticas) e eleger a Direção.

Atualmente, a CMP atua em 15 estados. Os movimentos populares em torno da Central são variados e vão desde ONGs de mulheres, movimentos de negros, moradia e comunitários, passando pelos movimentos culturais, de rádios comunitárias, indígenas e ecológicos, dentre outros, propondo diretrizes gerais para as lutas a serem travadas em cada momento específico, colaborando com a construção de um projeto político popular de transformação social.

A Confederação Nacional das Associações de Moradores (CONAM) foi fundada em 17 de janeiro de 1982; organiza as federações estaduais, uniões municipais e associações comunitárias e entidades de bairro. A CONAM congrega no presente mais de 550 entidades municipais e 22 federações estaduais, marcando presença em 23 estados da federação e no Distrito Federal. Em 2008, realizou o seu 10 ㅇ Congresso e reuniu 2,7 mil delegados.

A União Nacional por Moradia Popular está organizada em 19 estados brasileiros e iniciou suas atividades em 1989. Consolidou-se no movimento por meio de coletas de assinaturas para o primeiro Projeto de Lei de Iniciativa Popular, que criou o Sistema, o Fundo e o Conselho Nacional por Moradia Popular no Brasil (Lei 11.124/05).

Com esta tarefa os movimentos de moradia do estado do Paraná, São Paulo e Minas Gerais iniciam com objetivo de articular e mobilizar os movimentos de moradia, lutar pelo direito à moradia, por reforma urbana e autogestão e assim resgatar a esperança do povo rumo a uma sociedade sem exclusão social. Sua atuação se dá nas áreas de favelas, cortiços, sem-teto, mutirões, ocupações e loteamentos. $^{7}$

A União Nacional por Moradia Popular tem base nos estados e articula movimentos populares de moradia em suas diversas expressões - movimentos de sem-teto, cortiços, favelas, loteamentos, mutirões e ocupações.

Os movimentos citados têm em comum diversos aspectos: a capacidade de organização em todo o território nacional; a origem no interior das lutas pela Reforma Urbana dos anos de 1980; a congregação de movimentos locais diversificados sem os amarrar em uma estrutura decisória hierarquizada; e a realização 
de congressos periódicos como momentos principais de elaboração das lutas coletivas.

A participação dos movimentos populares pode ser detectada não apenas pelos números de entidades, mas também pela qualidade do envolvimento de seus militantes em manifestações de massa por melhores condições da vida urbana. No momento das conferências, por agirem como delegações, as entidades ganham visibilidade e destacam-se entre os delegados; participam levando as cores do movimento e palavras de ordem de identificação.

\section{Considerações Finais}

Ao fazer 20 anos de sua promulgação, em 2008, a Constituição Brasileira foi comemorada e elogiada, fato que não ocorrera em datas anteriores. A sociedade reconhece méritos importantes em seu texto, notadamente ao possibilitar aestruturação de instrumentos de controle social sob as políticas públicas.

Os dados aqui reunidos buscam apontar o extraordinário vigor da esfera pública e dos movimentos sociais em torno da questão urbana. O ConCidades apresenta-se como um formato participativo que inova em relação a outros Conselhos e fóruns e pressupõe um sistema de participação e representação democrático. Torná-lo deliberativo significa um avanço importante para a Política Urbana.

Há um inegável acúmulo de práticas participativas, mas o desafio está no que os eixos da 4ạ Conferência apontaram: fazer cumprir a legislação existente, garantir a integração das políticas e do controle social por meio da implementação dos conselhos temáticos em todo o território nacional e em todos os níveis de governo.

Apesar da intensidade das propostas e do envolvimento de sujeitos coletivos na construção de um sistema nacional de desenvolvimento urbano, os avanços são lentos com disputas de projetos muitas vezes conflitantes. Um exemplo basilar foi o longo caminho percorrido para a aprovação do Plano Nacional de Habitação de Interesse Social e os desdobramentos de sua implementação pactuados com a sociedade.

O perigo que ronda a iniciativa encontra-se, justamente, no campo da política institucional e nos jogos de interesses inerentes. A implantação do Programa de Aceleração do Crescimento (PAC), no início de 2007, causou apreensão já que foi uma iniciativa do Executivo Federal, mas pouco articulada aos planejamentos das pastas envolvidas. O Programa buscou dinamizar a economia e pressupunha uma série de investimentos em infraestrutura, com a rápida canalização de re- 
cursos para estados e municípios.

O entendimento é que houve um atropelo de políticas já em andamento, principalmente no âmbito do Ministério das Cidades, como a estruturação de uma Política Nacional de Habitação, por meio do Plano Nacional de Habitação, assim como do Sistema e do Fundo Nacional de Habitação de Interesse Social (FNHIS). A própria equipe ministerial veio a se fragmentar com a chegada do PAC.

O PAC também ignorou os Conselhos Setoriais já instituídos, seja em âmbito nacional, estadual ou municipal. Não foram sistematizados mecanismos que garantissem uma consulta prévia que envolvesse a sociedade civil para a aprovação dos projetos a serem acolhidos pelos recursos do PAC.

As questões apontadas acima não se resolvem por meio de números positivos. Parece-nos que vultosos recursos distribuídos em desacordo com o que fora anteriormente pactuado com a sociedade e os movimentos sociais apenas alimentam o paroquialismo característico de séculos de política brasileira, em contraposição ao universalismo de procedimentos apontados no texto do PAC. Na prática, ainda permanece a busca de verbas pelos que têm trânsito político. Os chefes dos executivos colocam-se com os únicos responsáveis por conseguir verbas para a localidade. Sem a responsabilidade, portanto, de dialogar com a sociedade os destinos dos recursos e o desenho da política. Nesse sentido, entendemos que o futuro deva ser um momento de inflexão e mudança de direcionamento para um planejamento pactuado com a sociedade, e não apenas com a classe política.

Referências bibliográficas

AVRITZER, L. (org.). A participação em São Paulo. São Paulo: Editora Unesp, 2004.

BENEVIDES, M. V. "Democracia e cidadania". Polis, Instituto de Estudos, Formação e Assessoria em Políticas Sociais, no 14, 2004, p. 11-19.

BONDUKI, N. "Política habitacional e inclusão social no Brasil: revisão histórica e novas perspectivas no governo Lula". Arq.urb - Revista eletrônica de Arquitetura e Urbanismo, no 1, 2008. Disponível em http://www.usjt.br/arq.urb/. Acesso em 02/05/2009.

Brasil. Ministério das Cidades. Secretaria Nacional de Habitação. Déficit habitacional no Brasil 2008 / Ministério das Cidades. Secretaria Nacional de Habitação. Elaboração: Fundação João Pinheiro, Centro de Estatística e Informações. Dispo- 
nível em www.fjp.gov.br. Acesso em 12/04/2010.

DAGNINO, E. (org.) Sociedade Civil e espaços públicos no Brasil. São Paulo: Paz e Terra, 2002.

DAGNINO, E.; Olvera, A.; Panfichi, A. (orgs.) A disputa pela construção democrática na América Latina. São Paulo: Paz e Terra, 2006.

ESTATUTO DA CIDADE (lei no 10.257, de 10/07/2001) - Regulamenta os artigos 182 e 183 da Constituição Federal, que estabelecem diretrizes gerais da política urbana e dão outras providências.

FLEURY, S. "Iniciativa Popular". In Avritzer, L.; Anastásia, F. (orgs.) Reforma Política no Brasil. Belo Horizonte: Editora UFMG, 2006, p. 94-98.

FUNGERIK, A.; Wright, E. "Experimentos em democracia deliberativa". Sociologias, no 2, Porto Alegre, UFRGS, 1999, p. 100-143.

GIDDENS, A. Sociologia. Porto Alegre: Artmed, 2005.

LAVALLE, A. G. "Sem pena nem glória. O debate sobre a sociedade civil nos anos 90". Novos estudos, São Paulo, no 66, 2003, p. 91-109.

LAVALLE, A. G.; CASTELLO, G.; BICHIR, R. M. "Quando novos atores saem de cena. Continuidades e mudanças na centralidade dos movimentos sociais". Revista Política e Sociedade, Florianópolis, v. 1, no 5, 2004, p. 35-54.

MINISTÉRIO DAS CIDADES. Cadernos MCidades, n 4, 2004 - Habitação. Disponível em www.cidades.gov.br/secretarias-nacionais/secretaria-de-habitação. Acesso em 23/02/2009.

MINISTÉRIO DAS CIDADES. Pacto Nacional pelo Saneamento Básico. Plano Nacional de Saneamento Básico (Plansab), 2008. Disponível em www.cidades.gov. br/ministerio-das-cidades. Acesso em: 23/02/2009.

MINISTÉRIO DAS CIDADES. Conselho Nacional das Cidades. Relatório final da 3ạ . Conferência das Cidades: desenvolvimento urbano com participação popular e justiça social/avançando na gestão democrática das cidades. Brasília: Secretaria Executiva do Conselho das Cidades, 2008.

MOURA, J. T. V.; SILVA, M. K. "Atores sociais em espaços de ampliação da democracia: as redes sociais em perspectiva". Revista de Sociologia e Política, Curitiba, v. 16,2008, p. 43-55.

NASCIMENTO, C.; SANTOS Jr., O.; FERREIRA, R. F. "O sistema nacional de desenvolvimento urbano e os conselhos estaduais das cidades: avanços e limites na 
descentralização dos canais de participação". Proposta - Revista Trimestral de Debate da Fase, no 116, 2008, p. 12-19.

PINTO, C. R. "Espaços deliberativos e a questão da representação". Revista Brasileira de Ciências Sociais, vol. 19, no 54, 2004, p. 97-113.

RIBEIRO, L. C. Q.; Santos Jr., O. A. (orgs.) Globalização, fragmentação e reforma urbana: o futuro das cidades brasileiras na crise. Rio de Janeiro: Civilização Brasileira, 1994.

ROLNIK, R. “Morar, atuar e viver”. Teoria e Debate, no 9, 1990, p. 98-119.

SADER, E. "Autonomia popular e vontade política". Desvios, no 2, 1983, p. 97103.

Quando novos personagens entraram em cena. Rio de Janeiro: Paz e Terra, 1988.

SANTOS, B. S. "Reinventar a democracia: entre o pré-contratualismo e o pós-contratualismo". In Oliveira, F.; Paoli, M. C. (Orgs.) Os sentidos da democracia: política do dissenso e hegemonia global. Petrópolis: Vozes, 1999.

SANTOS, B. S. A gramática do tempo - para uma nova cultura política. São Paulo: Cortez Editora, 2006.

TONELLA, C. "O Sistema de Desenvolvimento Urbano no Brasil e a participação popular nos últimos 20 anos". XIII ENANPUR - Planejamento e Gestão do território. Anais XIII ENANPUR - Planejamento e Gestão do território. Florianópolis, 2009. Disponível em http://www.xiienanpur.ufsc.br

YOUNG, I. Inclusion and democracy. Oxford: Oxford University Press. 2000. 